\title{
School accountability: can we reward schools and avoid pupil selection?*
}

\author{
Erwin Ooghe and Erik Schokkaert ${ }^{\dagger}$
}

July 2015

\begin{abstract}
School accountability schemes require measures of school performance, and these measures are in practice often based on pupil test scores. It is well-known that insufficiently correcting these test scores for pupil characteristics may provide incentives for pupil selection. Building further on results from the theory of fair allocation, we show that the trade-off between reward and pupil selection is not only a matter of sufficient information. A school accountability scheme that rewards school performance will create incentives for pupil selection, even under perfect information, unless the educational production function satisfies an (unrealistic) separability assumption. We propose different compromise solutions and discuss the resulting incentives in theory. The empirical relevance of our analysis - i.e., the rejection of the separability assumption and the magnitude of the incentives in the different compromise solutions - is illustrated with Flemish data. The traditional value-added model turns out to be an acceptable compromise.
\end{abstract}

Keywords: school accountability, cream-skimming, educational production function.

${ }^{*}$ We would like to thank Ides Nicaise and Jan Van Damme for their permission to use the SiBO-data, Frederik Maes and Peter Helsen for their valuable help with the data, and the editor, two anonymous referees, Dolors Berga, Geert Dhaene, Carmen Herrero, Iñigo IturbeOrmaetxe, Dirk Van de gaer, Frank Vandenbroucke, Carine Van de Voorde, and seminar participants in Alicante, Leuven, Louvain-la-Neuve, Oxford, and Rome for useful comments.

†Erwin Ooghe: Department of Economics (KU Leuven) and ZEW (Mannheim); erwin.ooghe@kuleuven.be. Erik Schokkaert: Department of Economics (KU Leuven) and CORE (Université Catholique de Louvain); erik.schokkaert@kuleuven.be. 
JEL-codes: H52, I22, I24.

\section{Introduction}

Public education used to have some common features around the world. Schools often received funding per pupil and had limited autonomy, inspectors controlled the quality of education, and school choice by parents was often restricted. Critics argued that these features explained the poor performance of (some) public schools.

School accountability increased in several countries to improve student learning. In the U.S., for example, the 'No Child Left Behind Act of 2001' forced all states to set up an accountability system for public schools. In some states schools had to publish report cards - information about their performance based on pupil test scores - to inform parental school choice. Other states used financial bonuses or sanctions depending on school performance.

School accountability improved pupil test scores, but it is unclear whether explicit financial bonuses and sanctions are necessary (Wössmann, 2003; Hanushek and Raymond, 2004, 2005; Jacob, 2005; Figlio and Rouse, 2006; West and Peterson, 2006; Burgess et al., 2007; Chiang, 2009). Accountability can also result in potentially undesirable strategic reactions such as teaching to the rating, student retainment, removal of low-achieving students, and even adapting the caloric content of the school lunches at the testing date (Jacob, 2005; Figlio and Winicki, 2005; Burgess et al., 2005; Reback, 2008). In a nutshell, the overall success of incentive-based reforms depends crucially on their design.

We focus on one possible strategic reaction of schools, pupil selection. The average test score in a school strongly depends on the characteristics of the pupil population. Insufficiently correcting for pupil characteristics may lead to a biased evaluation of school performance (Meyer, 1997; Ladd and Walsh, 2002; Hanushek and Raymond, 2003; Taylor and Nguyen, 2006; Neal, 2008). Moreover, it can give incentives to schools to appear more attractive for specific student groups. Pupil selection may then improve the measured performance of a school without adding real skills.

There is a fundamental conflict between rewarding schools and avoiding pupil selection, irrespective of whether the information to sufficiently correct for pupil 
characteristics is available. ${ }^{1}$ This problem is formally similar to the well-known conflict between "responsibility" and "compensation" axioms in the theory of fair allocation and equality of opportunity (see, e.g., Fleurbaey, 2008). While the latter theory is focused on the allocation of resources to individuals, we apply it to a setting in which resources have to be allocated to institutions, more specifically schools. A similar extension of the model to health insurance was already explored by Schokkaert et al. (1998) and Schokkaert and Van de Voorde $(2004,2009)$. These applications illustrate the flexibility of the fair allocation approach. In fact, from an ethical point of view, it may be better acceptable to impose some responsibility on institutions, rather than on individuals.

In section 2 we show that it is possible to reward schools with a higher output and eliminate incentives for pupil selection, but only if the educational production function satisfies an (unrealistic) separability assumption. In general a trade-off is inevitable and we propose therefore some compromise solutions. These are closely related to the conditional-egalitarian and the egalitarianequivalent solutions in the theory of fair allocation (Fleurbaey, 2008). One family of solutions rewards schools for good administration, but does not necessarily eliminate all pupil selection. The well-known value-added scheme is a special case. The other family avoids pupil selection, but does not necessarily reward schools for good administration. In section 3 we illustrate the empirical relevance of the trade-off and simulate the incentives provided by the different compromise solutions with empirical data for Flanders (the northern part of Belgium). The value-added scheme turns out to be an attractive compromise solution. Section 4 concludes.

\section{Accountability and incentives}

We construct a simple model to show the incompatibility between on the one hand creating incentives for higher test scores and on the other hand avoiding incentives for pupil selection. To bring the key trade-off into focus we start from the most favorable informational assumptions. We assume that sufficient data are available at the pupil level, as it is already well known that informationally

\footnotetext{
${ }^{1}$ We will focus on school financing schemes, but the question is equally relevant for the design of report cards. It could also be relevant for designing differentiated vouchers (Epple and Romano, 2008).
} 
less demanding accountability schemes cannot sufficiently correct for differences in pupil characteristics (Meyer, 1997; Hanushek and Raymond, 2003). Furthermore the selection of relevant pupil test scores and their aggregation (over different dimensions and pupils) into a cardinal and comparable indicator of school output is assumed to be settled (Cawley et al., 1999; Neal, 2008). We also neglect the problem that school output measures are typically less reliable for small schools (Kane and Staiger, 2002). Introducing these optimistic assumptions strengthens our impossibility result.

\subsection{Preliminaries}

The agreed measure of school output $y \in \mathbb{R}$ is a function of school variables denoted by $x \in X$; we write $y=f(x)$. School variables consist of administration variables $a \in A$ and background variables $b \in B$; we write $x=(a, b)$, and define the set $X$ as the product $A \times B$. The classification of a school variable as an administration or background variable is simple in theory. Endogenous variables that can be influenced by a school are attributed to administration; for example, the number of instruction hours, the level of remediation per pupil, and teacher motivation. Exogenous variables - variables that cannot be changed by a school, but whose distribution at school can possibly be altered by selection mechanisms - belong to background; think of initial test scores, innate intelligence, and socioeconomic status of the pupils. Because most background variables are directly related to characteristics of the pupils, we use the term pupil background from now on.

The distinction between administration and background variables is less evident in empirical applications. Usually, the function $f$ will be estimated via a standard explanatory model of test scores; see, e.g., Hanushek (2006) for an overview. A typical estimation includes observable characteristics, unobserved pupil and school effects, and idiosyncratic error terms. Each of these right-hand side variables, observed and unobserved, must be classified as an administration or a background variable. ${ }^{2}$ We will make a specific proposal in the next (empirical) section, but for the theoretical analysis it is sufficient to assume that some classification is made. ${ }^{3}$

\footnotetext{
${ }^{2}$ See Lefranc et al. (2009) for an alternative approach in which luck is not classified as either "responsibility" or "compensation", but treated as a separate category.

${ }^{3}$ We do not impose any restrictions on the function $f$. It is natural to define the variables
} 
We do not explicitly model school behavior (as, e.g., in Barlevy and Neal, 2011). The output function $f$ is a reduced form equation that reflects the educational production technology. We assume that $f$ does not change under the incentive scheme. Changes in subsidies can of course motivate schools to be more effective, otherwise the whole exercise would be meaningless. Changes may also induce incentives for pupil selection. Both effects are fully captured in our framework by a change in the administration variables in $a$ and pupil background characteristics in $b$.

We use subscripts $j=1,2, \ldots, J$ to denote schools. A school subsidy scheme $s: X^{J} \rightarrow \mathbb{R}^{J}$ maps all information about the different schools $\mathbf{x}=\left(x_{1}, x_{2}, \ldots, x_{J}\right)$ into a vector of school subsidies $s(\mathbf{x})=\left(s_{1}(\mathbf{x}), s_{2}(\mathbf{x}), \ldots, s_{J}(\mathbf{x})\right)$. We look for a subsidy scheme that rewards schools for better output without providing incentives to attract or refer pupils with specific characteristics. What form should $s(\mathbf{x})$ take? To answer this question, we do not start from an overall social objective function, but we model the requirements to be imposed on the school financing scheme directly in terms of two basic principles. We first formulate the basic principles, then show that they are incompatible in general, and finally introduce some possible compromise solutions.

This axiomatic approach (in terms of principles) is in line with the common approach in the theory of fair allocation. First, one explicitly formulates basic requirements to be imposed on a desirable allocation and afterwards one tries to find solutions that satisfy these requirements. This framework does not help in evaluating formally the trade-off between different principles, if they cannot be satisfied at the same time. We do not extend the approach to arrive at a complete social ordering of financing schemes. This question is left for future work. However, from an applied policy point of view, a less formal, but still structured evaluation of the trade-off may have considerable advantages. In our empirical work we will discuss the outcomes for different compromise solutions. This can be seen as a sensitivity analysis, giving the decision-makers all the results they need to take an informed decision.

$a$ and $b$ in such a way that they have a positive monotonic effect on school output, but this is not needed for our results. 


\subsection{Getting the incentives right}

We start with the reward principle. An increase in the output of a school that is caused only by a change in administration should increase the school subsidy. Let $(\mathbf{a}, \mathbf{b})$ denote the decomposition of $\mathbf{x}$ (with obvious notation).

incentives fOR GOOD administration: For all $\mathbf{x}, \mathbf{x}^{\prime}$ in $X^{J}$, for all $j=$ $1,2, \ldots, J$, if $a_{k}=a_{k}^{\prime}$ for each school $k \neq j$, and $\mathbf{b}=\mathbf{b}^{\prime}$, then $s_{j}\left(\mathbf{x}^{\prime}\right) \geq s_{j}(\mathbf{x})$ if and only if $y_{j}^{\prime} \geq y_{j}$.

The axiom does not say that the subsidy increase should be sufficiently large to make the cost (if any) of the change in administration worthwhile. It simply says that good administration should be financially encouraged. It can be interpreted as a minimalist necessary condition for efficiency. ${ }^{4}$

For later use, if the subsidy functions $s_{j}$ and the output function $f$ are differentiable with respect to some administration variable $a_{j k}$-an element in $a_{j}=\left(\ldots, a_{j k}, \ldots\right)$-then the axiom relates the marginal output to the marginal subsidy, or

$$
\partial s_{j}(\mathbf{x}) / \partial a_{j k} \geq 0 \text { if and only if } \partial f\left(x_{j}\right) / \partial a_{j k} \geq 0,
$$

for all profiles and schools.

We now turn to pupil selection. Changes in the background of pupils without changes in administration efficiency should not be rewarded in the funding scheme. Otherwise schools would have an incentive to attract or refer pupils with a specific background.

no incentives for PUPil Selection: For all $\mathbf{x}, \mathbf{x}^{\prime}$ in $X^{J}$, for all $j=1,2, \ldots, J$, if $\mathbf{a}=\mathbf{a}^{\prime}$, and $b_{k}=b_{k}^{\prime}$ for each school $k \neq j$, then $s_{j}\left(\mathbf{x}^{\prime}\right)=s_{j}(\mathbf{x})$.

The principle clearly wipes out all financial incentives for pupil selection. In general such pupil selection is undesirable, as it may lead to unequal treatment of pupils within schools, to segregation, and to restrictions on the freedom of choice of pupils and parents. Note however that a normative trade-off can arise if the segregation or integration of pupils over schools would increase average school output. Incentives for pupil selection could then be desirable from an efficiency point of view. We will come back to this issue when we discuss compromise solutions that allow for pupil selection.

\footnotetext{
${ }^{4}$ Note that for the axiom to be meaningful, it is not necessary that increases in $a$ have a positive effect on school output. If they have not, decreases in $a$ will be rewarded.
} 
Given differentiability with respect to a pupil background variable $b_{j k}$-an element in $b_{j}=\left(\ldots, b_{j k}, \ldots\right)$-the axiom imposes no subsidy changes at the margin, or

$$
\partial s_{j}(\mathbf{x}) / \partial b_{j k}=0
$$

for all profiles and schools.

\subsection{Performance incentives create selection incentives}

The two principles seem minimal if the aim is to create incentives for good administration and to avoid pupil selection at the same time. It is therefore striking that it is not possible to design a funding scheme that satisfies both principles in general, i.e., for all possible output functions $f$. As mentioned before, this impossibility result is well known (in many variants) in the social choice literature (Fleurbaey, 2008). Yet it remained largely unnoticed in the literature on school accountability. Meyer (1997) is the only one, as far as we know, that has drawn attention to the fact that schools cannot be ranked unambiguously according to performance, if the effect of background variables on output differs between them, but he did not integrate this observation in a general theoretical framework. ${ }^{5}$

We provide a simple proof of the incompatibility between the two incentive axioms. We focus on an arbitrary school, keeping information on all other schools constant. We suppress subscripts, and, with a slight abuse of notation, we denote the output and the subsidy of the school by $f(a, b)$ and $s(a, b)$. Let $b \in B=\mathbb{R}$ be an index of pupil background at the school. Figure 1 presents school output as a function of pupil background for two types of administration $a$ and $a^{\prime}$.

\section{Figure 1}

Start at situation 1 with administration $a$ and pupil background $b$. An increase in the background index from $b$ to $b^{\prime}$ leads us to situation 2. The axiom NO INCENTIVES FOR PUPIL SELECTION requires the same subsidy in both situations, thus $s(a, b)=s\left(a, b^{\prime}\right)$. If the school would now change administration from $a$ to $a^{\prime}$, ceteris paribus, then we go from situation 2 to 3 with a lower output.

\footnotetext{
${ }^{5}$ Moreover, Meyer (1997) claims that the empirical relevance of his observation is limited because "the assumption that slopes do not vary across schools is often a very reasonable assumption." In the next section, we falsify this claim with Flemish data.
} 
The axiom INCENTIVES FOR GOOD ADMINISTRATION requires a lower subsidy leading to $s\left(a, b^{\prime}\right)>s\left(a^{\prime}, b^{\prime}\right)$. If the school sticks to administration $a^{\prime}$, but the pupil background index changes back to $b$, then we arrive in situation 4. Again the same subsidy should apply, so $s\left(a^{\prime}, b^{\prime}\right)=s\left(a^{\prime}, b\right)$. Finally, a change in administration back to $a$, ceteris paribus, lowers output again, and the subsidy must follow, or $s\left(a^{\prime}, b\right)>s(a, b)$. All things together we get a cycle. Proposition 1 summarizes this finding.

Proposition 1. There is no subsidy scheme that satisfies incentives for GOOD ADMINISTRATION and NO INCENTIVES FOR PUPIL SELECTION in general, i.e., for each possible output function $f$.

Proposition 1 has to be interpreted carefully: the general impossibility result only holds if we look for a subsidy scheme satisfying both axioms for all possible output functions $f$. It is obvious that the incompatibility disappears in Figure 1 if the lines would not intersect. Proposition 2 generalizes this observation (a proof can be found in the appendix).

Proposition 2. A subsidy scheme can satisfy InCEntives FOR GOOD ADMinISTRATION and NO INCENTIVES FOR PUPIL SELECTION if and only if there exist functions $g: \mathbb{R} \times B \rightarrow \mathbb{R}$ and $h: A \rightarrow \mathbb{R}$, with $g$ strictly increasing in its first argument, such that $f(a, b)=g(h(a), b)$, for all $x=(a, b)$ in $X$.

The intuition is easy. The separability condition in Proposition 2 allows to unambiguously classify schools according to performance $h(a)$ : a higher value for $h(a)$ corresponds with a higher output, irrespective of the background of the pupils. If we define each subsidy $s_{j}(\mathbf{x})$ to be a strictly increasing function of the school performance index $h\left(a_{j}\right)$, then both requirements will be satisfied by the resulting subsidy scheme.

The actual relevancy of Propositions 1 and 2 is an empirical question. The separability condition in Proposition 2 is implicitly imposed by the simple linear models that are often used to estimate educational production functions. If this linearity assumption holds, there is no conflict between our two axioms, but falsely assuming a linear form may have undesirable consequences in terms of school administration and pupil selection. It is therefore important not to simply assume separability, but to test whether it holds.

Proposition 2 gives a necessary and sufficient condition for the subsidy scheme to satisfy both axioms if $a$ and $b$ can take any values in their respective 
domains $A$ and $B$. In reality, the values taken by the observed administration and background variables for a school fall in a more restricted range. So, even if separability is rejected by the data, one cannot immediately draw the conclusion that there is a conflict over the restricted range. Accordingly, we will test separability in section 3 in two ways. Applied to Figure 1, a first test verifies whether both lines are parallel; if not, they must cross somewhere. A second test looks whether the lines cross in the actual data range.

\subsection{Compromise solutions}

If there is a conflict between the two principles, we have to formulate compromise solutions. We can keep the incentives for good administration intact, but then we may introduce incentives for selecting pupils with a certain background. Or we can make sure that we avoid selection, but then the incentives to improve pupil learning can be very different for different pupils and may even become negative.

For ease of exposition, we suppress in our notation the dependency of the subsidies on the profile $\mathbf{x}$. We use linear subsidy schemes from now on and write the per pupil subsidy for school $j$ as

$$
s_{j}=\text { constant }+\underbrace{\text { slope }}_{>0} \times \widetilde{y}_{j}
$$

with $\widetilde{y}_{j}$ the (possibly corrected) output of school $j$ that will be defined later on. In this section we leave the choice of the constant and the slope open. One option is to set the constant to satisfy the budget constraint of the regulator, and the slope to guarantee a minimal subsidy to all schools. This is the approach that will be followed in the empirical application, but for the theoretical analysis these choices are irrelevant.

Before we propose two families of compromise solutions, we discuss two benchmark subsidy schemes: per capita $(P C)$ and uncorrected output $(U O)$ funding. In many countries school funding is simply per capita, i.e.,

$$
s_{j}^{P C}=\text { constant. }
$$

A per capita scheme does not provide any incentives, neither for good administration, nor for pupil selection. An uncorrected output scheme fully rewards schools for output increases, without any correction for pupil background. The 
subsidy is equal to

$$
s_{j}^{U O}=\text { constant }+ \text { slope } \times \underbrace{f\left(a_{j}, b_{j}\right)}_{y_{j}} .
$$

The scheme gives incentives for good administration, because changes in administration that lead to higher output clearly will be rewarded. Assuming differentiability we obtain

$$
\partial s_{j}^{U O} / \partial a_{j k}=\text { slope } \times \partial f\left(a_{j}, b_{j}\right) / \partial a_{j k},
$$

and, given that slope $>0$, condition (1) is indeed satisfied. For the same reason however, also changes in background that lead to higher output will be rewarded. Schools have an incentive to attract pupils with a background that is 'favorable' to output. Given differentiability the subsidy change is equal to

$$
\partial s_{j}^{U O} / \partial b_{j k}=\text { slope } \times \partial f\left(a_{j}, b_{j}\right) / \partial b_{j k},
$$

violating condition (2) if $\partial f\left(a_{j}, b_{j}\right) / \partial b_{j k}$ differs from zero.

A first family of compromise solutions is based on a reference administration $(R A)$ level, denoted $\widetilde{a}$, to correct output. Define corrected output as $\widetilde{y_{j}}=y_{j}-$ $f\left(\widetilde{a}, b_{j}\right)$; the subsidy is then equal to

$$
s_{j}^{R A}=\text { constant }+ \text { slope } \times(\underbrace{f\left(a_{j}, b_{j}\right)}_{y_{j}}-f\left(\widetilde{a}, b_{j}\right)) .
$$

Schools are rewarded if their output is higher than the hypothetical output that would result if the school had chosen the reference administration level, ceteris paribus. The scheme creates incentives for good administration, because changes in administration that are favorable to output translate into higher subsidies. Assuming differentiability of the reference scheme, the incentive for good administration $\partial s_{j}^{R A} / \partial a_{j k}$ is exactly equal to the one for uncorrected output in equation (6). Reference administration schemes may lead to selection incentives, however. The selection incentive depends on

$$
\partial s_{j}^{R A} / \partial b_{j k}=\text { slope } \times\left(\partial f\left(a_{j}, b_{j}\right) / \partial b_{j k}-\partial f\left(\widetilde{a}, b_{j}\right) / \partial b_{j k}\right),
$$

and will typically be different from zero, thus violating (2). Comparing (7) and (9), if the derivatives $\partial f\left(a_{j}, b_{j}\right) / \partial b_{j k}$ and $\partial f\left(\widetilde{a}, b_{j}\right) / \partial b_{j k}$ are similar in sign and magnitude, then $\left|\partial s_{j}^{R A} / \partial b_{j k}\right|$ will be smaller than $\left|\partial s_{j}^{U O} / \partial b_{j k}\right|$. Summing up, 
reference administration schemes provide similar incentives for good administration compared to uncorrected output schemes, but are likely to provide lower incentives for pupil selection.

The mirror image of the previous scheme is to choose a reference pupil background $(R B)$, say $\widetilde{b}$. If we define corrected output as $\widetilde{y_{j}}=f\left(a_{j}, \widetilde{b}\right)$, then schools will be rewarded on the basis of the hypothetical output that would arise if its actual administration were applied to the reference pupil population. This yields

$$
s_{j}^{R B}=\text { constant }+ \text { slope } \times f\left(a_{j}, \widetilde{b}\right) .
$$

The subsidy $s_{j}^{R B}$ does not depend on the school background $b_{j}$ anymore, which removes selection incentives. With differentiability, we indeed get $\partial s_{j}^{R B} / \partial b_{j k}=$ 0 as required by (2). But actual output does not appear in equation (10) either. We can immediately derive that

$$
\partial s_{j}^{R B} / \partial a_{j k}=\text { slope } \times \partial f\left(a_{j}, \widetilde{b}\right) / \partial a_{j k}
$$

and condition (1) is no longer satisfied if the change in the true output, being $\partial f\left(a_{j}, b_{j}\right) / \partial a_{j k}$, has a different sign compared to the change in the hypothetical output $\partial f\left(a_{j}, \widetilde{b}\right) / \partial a_{j k}$. Because we expect that the signs of both derivatives often coincide, the reference background scheme will provide more incentives for good administration compared to a per capita scheme. Summing up, reference background schemes provide no incentives for pupil selection, as is the case in a per capita scheme, but in addition they can be expected to provide some incentives for good administration.

Table 1 summarizes the different schemes and their properties, i.e., is the axiom satisfied, how large do we expect the incentives to be, and for how many schools will the axioms be satisfied? Per capita schemes do not give incentives for good administration nor incentives for pupil selection to any school. Uncorrected output schemes give both incentives to all schools. We expect the reference schemes to do better. More precisely, reference administration schemes outperform the uncorrected output schemes, because they give the same incentives for good administration to all schools, but with less incentives for pupil selection. Reference background schemes outperform per capita schemes, because they provide no incentives for pupil selection, but more incentives for good administration.

Table 1 
While we expect reference administration and reference background schemes to be better than the simple benchmark schemes, they also require more information. More importantly, the extra information required by the schemes in equation (8) and (10) is also different. To implement these schemes, the regulator must have (an estimate of) the educational production function $f$. In addition, a reference administration scheme requires information about output $y_{j}$ and background variables $b_{j}$, while a reference background scheme needs information about the administration variables $a_{j}$. These different requirements may have practical consequences. A reference background scheme offers scope for strategic behavior, e.g., increasing instruction time without any real results. Even worse, it may create incentives for misreporting variables, like instruction time, that are difficult to verify. Strategic behavior is less problematic in a reference administration scheme. Test scores are collected in a standardized way and background variables typically consist of pupil characteristics that can more easily be controlled by the regulator.

A final note. The reference administration and reference background schemes are "families" of solutions, since we obtain one scheme for each specific choice of reference. The implications that have been described in this section hold for the complete family, but this does not mean that the choice of reference values is irrelevant. We will return to this issue in the next section.

\section{Empirical illustration}

We use data collected by the 'SiBO'-project in Flanders, the northern part of Belgium. The aim of the project is to describe and explain differences in the primary school curriculum of Flemish pupils. At the time of the survey, there were no school accountability schemes in Flanders that could create financial incentives for pupil selection by schools. However, parents are free to choose a school and schools care for their reputation. There are basically two school groups in Flanders: a group of public schools and a group of private, mainly catholic schools. Certainly for primary schools, the two groups are competing for pupils at the local level. Contrary to the situation in most other countries, public and private schools are both publicly financed and the difference between them is mainly ideological. There is evidence of sorting, as catholic schools attract more pupils with a favorable background. We will come back to that 
issue in our empirical work. Schools in the Flemish system have a reasonable amount of autonomy to decide about their own practical organization.

In the 'SiBO'-project, pupils were tested in mathematics at the start of the first grade (in September-October 2003 when (most) pupils were 6 years old) and at the end of grades 1 and 2 (in May-June of 2004 and 2005). ${ }^{6}$ We have 7591 pupil-time observations distributed over 125 schools. A subgroup of 3314 pupils are tested in both periods, 533 pupils in period 1 only, and 430 in period 2 only. The dynamics of attrition and replenishment are summarized in Figure 2. The main reason for attrition and replenishment is student retainment. We will test for this potential source of selection bias.

\section{Figure 2}

Our pupil data include the gender of the pupil, the language they speak with each of the parents, and the education level of the parents. ${ }^{7}$ Classroom data consist of the total experience of the teacher, the class size, the instruction time for mathematics, and the number of teachers in a class (either one full time or two halftime teachers). We also include the average initial test score of the peers, defined as all other pupils in the same class. For estimation purposes we restrict the sample to pupils with non-missing initial test scores and classroom data, that go to schools with at least 10 pupils tested in each grade. ${ }^{8}$ We are left with 5817 pupil-time observations - 2239 pupils appearing in both grades, 628 in grade 1 only, and 711 in grade 2 only - distributed over 111 schools. Table 2 describes all variables and Tables $3 \mathrm{a}$ and $3 \mathrm{~b}$ provide summary statistics.

\section{Table 2, 3a, and 3b}

\subsection{Explaining test scores: a linear exploration of the data}

Let $y_{i j t}$ be the (standardized) math test score of pupil $i$ at school $j$ at time $t$ and let $z_{i j t}$ be the vector of observable regressors. To explore the data, we start with a standard linear panel model, i.e.,

$$
y_{i j t}=\beta^{\prime} z_{i j t}+u_{i}+v_{j}+w_{i j t},
$$

\footnotetext{
${ }^{6}$ The math tests consists of between 40 and 80 questions (depending on the grade). The score distributions are well-behaved, showing no floor and only limited ceiling effects.

${ }^{7}$ Note that Dutch is the official language in Flanders.

${ }^{8}$ To limit the reduction in sample size, we add a dummy 'missing' in case of missing pupil level data (except for initial test scores). We will not report the corresponding estimates which are, as expected, never significant.
} 
with $u_{i}$ a 'random' pupil effect, $v_{j}$ a 'fixed' school effect, and $w_{i j t}$ an idiosyncratic error term. Following Mundlak (1978), we always add group means - averages of the time-varying covariates at the pupil level- to the specification. Standard errors are adjusted for clustering at the school level.

\section{Table 4}

Table 4 reports estimates of the parameters in equation (12). The initial test score plays an important role in all models. Its coefficient is rather robust and smaller than 1, indicating that the gain in test scores, is larger for pupils with a lower initial test score. The background variables play a more modest role and their effects depend on whether or not the initial test score is taken up as a covariate.

In model (b) without initial test scores, boys do better than girls. Having Dutch-speaking and more educated parents improve test scores and these effects are stronger and more significant for mothers compared to fathers.

In model (c) with initial test scores as an additional regressor, some of the estimated coefficients for the background variables change in magnitude and even in sign. We provide two striking examples. First, speaking Dutch with your parents has a negative coefficient once we correct for initial test scores. Indeed, pupils that do not speak Dutch at home have a worse preparation on average before starting primary education. Therefore their initial test score underestimates their potential, leading to a catching-up effect in the first grades. Second, the effect of fathers' education level is now stronger than that of mothers. This is consistent with the hypothesis that mothers have a larger effect on initial test scores during the pre-primary education period, while fathers have a larger effect on the primary education growth of their children.

Comparing models (c) and (d) shows that adding class level variables has a minor effect on the estimated coefficients for the background variables. In model (d), all class variables, except class size, have the expected sign, but none of the class variables is statistically significant.

\subsection{Selection and sorting}

The estimation procedure leading to the estimates in Table 4 neglects the issue of sorting and sample selection. The first column in Table 5 reproduces the 
estimates of model (d) reported in Table 4. Model (e) and model (f) in Table 5 correct for attrition/replenishment and for sorting respectively.

\section{Table 5}

The first issue relates to the attrition and replenishment in the SiBO-data. The results of a variable addition test (see, Verbeek and Nijman, 1992, and Wooldridge, 1995) indicate that missingness might be informative, especially for attrition. ${ }^{9}$ To check whether selection influences the estimation results, we estimate a selection equation in each period and add the generalized residuals to the output equation. To improve identification, we include regional dummies in the selection equation. Following Semykina and Wooldridge (2010), we allow the correlation between the unobserved pupil effects of the selection and the output equation to vary over time. In contrast to the variable addition test, the generalized residuals and time interactions together are not significant $\left(\chi^{2}(4)=\right.$ 2.10 with prob $>\chi^{2}$ equal to 0.72 ).

A second issue relates to the possibility of sorting. As described before, although there are no financial incentives to do so, the evidence suggests that private, mainly catholic schools, attract pupils with a stronger socioeconomic background. To check whether this sorting influences the estimation results we follow the same procedure as before. We estimate a selection equation (based on "being in a catholic school or not") in each period and add the generalized residuals (with time interactions) and the catholic school dummy to the output equation. ${ }^{10}$ Given that competition for pupils occurs at the local level and that school choice is mainly on ideological grounds, we include again the regional dummies in the selection equation together with religion dummies (catholic, protestant, jewish, islam, freemason, areligious) for both parents. The catholic school dummy in the output equation is positive, but not statistically significant. Interestingly, note that the coefficient for class size becomes negative, but remains statistically insignificant. ${ }^{11}$ The generalized residuals and time inter-

\footnotetext{
${ }^{9}$ The coefficient on a dummy "present in the first period" is 0.036 (s.e. 0.056) and hence is not significantly different from zero. The dummy "present in the second period" gets a highly significant estimated coefficient of 0.291 (s.e. 0.048). A $\chi^{2}$-test for joint significance of the two dummies yields $\chi^{2}(2)=39.67(p=0.00)$.

${ }^{10}$ The effect of being in a catholic school cannot be estimated with a full set of school dummies included. We therefore omit the school dummies in model (f).

${ }^{11}$ Including a quadratic term for class size reveals that class size has a negative effect up to a class size of (slightly more than) 23 pupils, covering almost $80 \%$ of all pupils in the sample.
} 
actions together are also not significant $\left(\chi^{2}(4)=4.07\right.$ with prob $>\chi^{2}$ equal to $0.40)$.

\subsection{Testing separability}

A linear specification, like equation (12), is common in the literature on educational production functions. It satisfies the separability condition of Proposition 2 , irrespective of how the right-hand variables are classified into administration and background variables. For the derivation of a financing scheme however, it is essential to test explicitly whether the separability condition holds.

To do so, we split the observables $z_{i j t}$ into administration and background variables, denoted $z_{a, i j t}$ and $z_{b, i j t}$. It is natural to assign variables at the class and school level - including the school-specific constant, but excluding the peer variable - to administration. All other variables - the pupil-level variables, the time dummy, and the peer variable - are classified as background. To test separability we generalize (12), allowing the pupil background coefficients to vary over schools, i.e.,

$$
y_{i j t}=\beta_{a}^{\prime} z_{a, i j t}+\beta_{b, j}^{\prime} z_{b, i j t}+u_{i}+v_{j}+w_{i j t}
$$

The specification with variable slope coefficients $\beta_{b, j}$ for each background variable is very flexible. Following Arcidiacono and Koedel (2014), a considerable simplification could be obtained by introducing an academic index for each pupil, say,

$$
I_{i j t}=\gamma^{\prime} z_{b, i j t}
$$

and rewriting equation (13) as

$$
y_{i j t}=\beta_{a}^{\prime} z_{a, i j t}+\beta_{j} I_{i j t}+u_{i}+v_{j}+w_{i j t} .
$$

The estimated coefficients $\widehat{\gamma}$ for the academic index (14) are given in Table 6 and look reasonable. ${ }^{12}$ However, the coefficient restrictions imposed by equations (14) and (15) are strongly rejected by a likelihood ratio test $\left(\chi^{2}(784)=1650.96\right.$ with $p=0.000)$. We therefore stick to the more general specification (13).

The estimated coefficients are -0.0394622 for class size and 0.0008517 for squared class size, but both together are not significant $\left(\chi^{2}(2)=0.33\right.$ with prob $>\chi^{2}$ equal to 0.85$)$.

${ }^{12}$ Note that they are normalized so that the coefficient for "girl" gets the value -1 . Absolute numbers are therefore not directly comparable to the estimates in Table 4, but the ratios between the coefficients are. 


\section{Table 6}

To see why equation (13) is not separable, suppose school output is equal to the expected average pupil output. Let a bar denote an average (with the subscript indicating at which level the average is taken) and let a hat indicate an estimate; school output is equal to

$$
\bar{y}_{j}=\widehat{\beta}_{a}^{\prime} \bar{z}_{a, j}+\widehat{\beta}_{b, j}^{\prime} \bar{z}_{b, j}+\widehat{v}_{j},
$$

where $\bar{y}_{j}$ is the average test score in school $j$. Since the slope coefficients $\widehat{\beta}_{b, j}$ tell us how pupils with a certain background perform at school $j$, it is natural to assign these coefficients to administration. ${ }^{13}$ We get:

$$
\bar{y}_{j}=\underbrace{\widehat{\beta}_{a}^{\prime} \bar{z}_{a, j}+\widehat{v}_{j}}_{\text {pure administration }}+\underbrace{\widehat{\beta}_{b, j}^{\prime} \bar{z}_{b, j}}_{\text {mixture }} .
$$

The non-linear terms in $\widehat{\beta}_{b, j}^{\prime} \bar{z}_{b, j}$ mix administration and background. They are crucial to test the separability condition in proposition 2. More precisely, separability is satisfied if the slope coefficients $\widehat{\beta}_{b, j}$ are the same for all schools. Table 7 summarizes the separability tests based on model (13). The 'equal slope'-hypothesis is statistically rejected, for each background variable separately as well as for all background variables jointly.

\section{Table 7}

Two remarks. First, as discussed in the previous section, it is possible that the former test rejects separability, but that there is no incompatibility between the two principles of INCENTIVES FOR GOOD ADMINISTRATION and NO INCENTIVES FOR PUPIL SELECTION within the range of actual observations. One could argue that in the latter case there is not really a problem, at least in the short and medium term. We therefore also check if the educational production functions for the schools in our sample significantly cross each other. We test this with respect to initial test scores. We first check, for each school, if its production function crosses the production function of another school in their common data range. If a crossing is present, we test if the slopes for the two schools are

\footnotetext{
${ }^{13}$ To avoid confusion, we stress that the subscript $b$ in the estimated slope vector $\widehat{\beta}_{b, j}$ indicates that it is a slope vector for the background variables. Still, these background slopes are at the school level and therefore classified as administration variables.
} 
significantly different. It turns out that for each school in our sample, except one, there is another school such that their production functions significantly cross. We conclude that the conflict between the two principles, as described in Figure 1, is empirically relevant in our sample.

Second, the performed separability test assumes a linear production function. If the linearity assumption is not true, different slopes for different schools would not necessarily mean that the production functions cross, but only that they are measured at different points of, e.g., a concave production function. We therefore repeat the separability test with a quadratic term for initial test scores. This analysis confirms that final test scores are indeed a concave function of initial test scores, but separability is again rejected. ${ }^{14}$

Because separability does not hold, incentives for good administration may create incentives for pupil selection and, vice-versa, removing incentives for pupil selection may create incentives for bad administration. We now turn to the practical relevance of the incompatibility. In particular, we will check to what extent the different subsidy schemes defined above satisfy the principles of INCENTIVES FOR GOOD ADMINISTRATION and NO INCENTIVES FOR PUPIL SELECTION and we look for the most attractive compromise solution.

\subsection{The trade-off in practice}

Recall the linear subsidy scheme defined in equation (3). Let us first operationalize its different interpretations within the context of the non-separable model (13). For this empirical application we have to specify the constant and the slope. The constant can be fixed by introducing the budget constraint faced by the regulator, i.e., by imposing that the average subsidy per pupil has to be equal to the available budget per pupil. If we normalize the available budget to be 1 unit per pupil, the per-pupil subsidy at school $j$ becomes

$$
s_{j}=1+\text { slope } \times\left(\widetilde{y}_{j}-\overline{\widetilde{y}}\right),
$$

with $\overline{\widetilde{y}}$ the average (corrected) output. ${ }^{15}$

To fix the slope, a natural constraint is to guarantee each school a minimal subsidy per pupil, say $\underline{s}$, with $0<\underline{s}<1$. A minimal subsidy requirement imposes

\footnotetext{
${ }^{14}$ The separability test statistic is $\chi^{2}(220)=558.38$ with prob $>\chi^{2}$ equal to 0.000 .

${ }^{15}$ Remember that if we define an average without a subscript, this is the average over the whole population, i.e. over all schools.
} 
an upper bound on the slope:

$$
\text { slope } \leq(1-\underline{s}) /\left(\overline{\widetilde{y}}-\min \widetilde{y}_{j}\right) .
$$

With $\underline{s}$ fixed, equation (17) will yield a different upper bound for slope, depending on the subsidy scheme used. To ease the comparison of the results for the different schemes, we choose slope to be equal to the lowest upper bound over the different schemes. Taking $\underline{s}=0.5$, we get a coefficient slope $(\approx 0.4)$ that is common to all schemes, but the minimal subsidy per pupil will differ slightly between the different schemes.

We can now provide a formula for each subsidy scheme. Denoting as before the reference levels by a tilde, we get (the derivations can be found in the appendix):

$$
\begin{aligned}
s_{j}^{P C} & =1, \\
s_{j}^{U O} & =1+\text { slope } \times\left(\bar{y}_{j}-\bar{y}\right), \\
s_{j}^{R A} & =1+\text { slope } \times\left\{\left(\bar{y}_{j}-\bar{y}\right)-\widetilde{\beta}_{b}^{\prime}\left(\bar{z}_{b, j}-\bar{z}_{b}\right)\right\}, \\
s_{j}^{R B} & =1+\text { slope } \times\left\{\left(\bar{y}_{j}-\bar{y}\right)-\widehat{\beta}_{b, j}^{\prime}\left(\bar{z}_{b, j}-\widetilde{z}_{b}\right)+{\overline{\widehat{\beta}_{b, j}}}_{b, j}\left(\bar{z}_{b, j}-\widetilde{z}_{b}\right)\right\} .
\end{aligned}
$$

As noted before, the reference levels in reference administration and reference background models can be chosen. These choices will have different implications for incentives. In the empirical illustration, the reference levels for slopes $\widetilde{\beta}_{b}$ and averages $\widetilde{z}_{b}$ are based on the distribution of the estimated coefficients $\widehat{\beta}_{b, j}$ and the averages $\bar{z}_{b, j}$ over the different schools. We choose the 5 th percentile (low), the median (mid), and the 95th percentile (high).

It is instructive to compare these solutions with what could be described as the common practice of using a value added $(V A)$ model. If one sticks to the (rejected) separable model

$$
y_{i j t}=\beta_{a}^{V A \prime} z_{a, i j t}+\beta_{b}^{V A \prime} z_{b, i j t}+u_{i}^{V A}+v_{j}^{V A}+w_{i j t}^{V A},
$$

then school output is predicted as

$$
\bar{y}_{j}=\widehat{\beta}_{a}^{V A \prime} \bar{z}_{a, j}+\widehat{\beta}_{b}^{V A \prime} \bar{z}_{b, j}+\widehat{v}_{j}^{V A} .
$$

The part $\widehat{\beta}_{a}^{V A \prime} \bar{z}_{a, j}+\widehat{v}_{j}^{V A}$ is usually considered to be the value-added of the school; see, e.g., Meyer (1997). If we define corrected output $\widetilde{y}_{j}$ as value added, the per pupil subsidy reduces to (see appendix)

$$
s_{j}^{V A}=1+\text { slope } \times\left\{\left(\bar{y}_{j}-\bar{y}\right)-\widehat{\beta}_{b}^{V A \prime}\left(\bar{z}_{b, j}-\bar{z}_{b}\right)\right\} .
$$


Comparing this value-added scheme with the reference administration subsidy scheme shows immediately that the former is a special case of the latter if one sets the reference coefficients $\widetilde{\beta}_{b}$ equal to the coefficients $\widehat{\beta}_{b}^{V A}$ estimated with the wrongly specified model (18). Since $\widehat{\beta}_{b}^{V A}$ will not be very different from the median value for $\widehat{\beta}_{b, j}$, the value-added scheme will have similar properties as the corresponding (median) reference administration scheme. It will create incentives for efficiency, but also incentives for pupil selection.

To check the extent to which these schemes satisfy the two basic principles in practice, we perform some simulations. These simulations are based on the estimates of model (d) in Table 5 and thus ignore selection bias (model (e)) and sorting bias (model (f)). Recall that the generalized residuals where not statistically significant either in model (e) or in model (f), so we could not reject the hypothesis of no selection and no sorting. More important for our purposes, the estimates in models (e) and (f) are close to the ones in model (d) and lead therefore to similar simulation results.

Because the results in Table 4 indicate that initial test scores and parental education correlate strongly with final test scores, we select these two variables for further analysis. The distribution of their slopes and averages over schools is given in Table 8. ${ }^{16}$ The simulation results are given in Tables 9 and 10 respectively. Because the simulation results for initial test scores and parental education are very similar, we only discuss those for initial test scores, reported in Table 9.

\section{Tables 8, 9, and 10}

A first simulation focuses on the subsidy change that might result from changing the administration of a school without changing the school output. This can be realized by increasing the slope of the background variable $\widehat{\beta}_{b, j}$ by one standard deviation and simultaneously decreasing the school fixed effect $\widehat{v}_{j}$ such that $\Delta \bar{y}_{j}=\Delta \widehat{\beta}_{b, j} \bar{z}_{b, j}+\Delta \widehat{v}_{j}=0$ holds. Applied to initial test scores, one could interpret this simulation as reflecting a more elitist school policy that shifts teaching effort from low to high (initial) achievers, without changing school output. The reverse, more egalitarian policy of decreasing the slope and simultaneously increasing the fixed effect can also be simulated. The results are identical in absolute value, but have an opposite sign.

\footnotetext{
${ }^{16}$ The reported slopes for average initial test scores include the peer effect. For parental education we include both the education of the mother and of the father.
} 
Because the output effect is zero by construction, INCENTIVES FOR GOOD ADMINISTRATION requires that this policy should not lead to an increase in the school subsidy. Table 9a shows the effect of the elitist policy on the school subsidies per pupil for the different subsidy schemes. To interpret the numbers, recall that the subsidies are normalized to be 1 on average. So, -0.08 or 0.06 can be interpreted as a loss or a gain equal to $8 \%$ or $6 \%$ of the average school subsidy. ${ }^{17}$ All subsidy changes should be interpreted as short-term changes, i.e., assuming that other schools do not change policy.

Table 9a shows that the reference administration $(R A)$ schemes-including the value added $(V A)$ scheme - and the uncorrected output (UO) scheme satisfy the reward principle. If output does not change, the subsidy does not change. However, this is not true for the reference background $(R B)$ schemes. The subsidy change depends on the choice of the reference value and can be negative or positive. If one chooses a low value for the reference $\widetilde{z}$, Table 9 a shows that $96 \%$ of the schools would receive less subsidies if they choose a more elitist policy. Because the egalitarian scheme has exactly the opposite consequences, $96 \%$ of the schools have therefore an incentive to choose more egalitarian policies in case of a low reference. If one chooses a high value for the reference, about $94 \%$ of the schools have an incentive to choose more elitist policies.

The problem of the $R B$ schemes is in fact more severe. Recall that the regulator can only apply these $R B$ schemes if she gets the necessary information about the administration variables from the schools themselves. This information is difficult to verify and easy to manipulate. It is therefore clear that there is a real danger that the $R B$ schemes are manipulated by the schools to receive a higher subsidy without a better performance.

A second simulation looks at the subsidy change resulting from a change in the pupil distribution of a school. We implement this hypothetical change by simulating the effect of increasing $\bar{z}_{b, j}$ by one standard deviation. ${ }^{18}$ Applied to initial test scores, the policy can be interpreted as attracting better pupils. Ideally, NO INCENTIVES FOR PUPIL SELECTION requires that the subsidy should not change, since schools should not be rewarded for pupil selection if there is no increase in administration efficiency.

\footnotetext{
${ }^{17}$ We do not report the results for the per-capita scheme, because per-capita subsidies obviously do not respond to the simulated changes.

${ }^{18}$ Again, the subsidy changes of decreasing, rather than increasing the average background characteristics are exactly the same, up to a minus sign.
} 
The change in subsidies for a change in initial test scores are given in Table 9b. With the reference background schemes, schools are not rewarded when changing their pupil composition (without changing their administration efficiency). However, the reference administration schemes and the uncorrected output scheme provide incentives for pupil selection. In case of uncorrected output for example, increasing the average initial test scores at school by one standard deviation may increase the subsidy up to $18 \%$ of the average school subsidy. The gains and losses in case of the reference administration schemes are typically smaller and depend on the reference slope. If the $R A$ scheme is implemented with a low reference value for the pupil background, almost all schools gain by attracting pupils with higher initial test scores. Choosing a high reference value implies that most schools would loose when attracting pupils with higher initial test scores, or symmetrically, that most schools would gain by attracting pupils with lower initial test scores.

The tables suggest that choosing a median reference level minimizes the absolute magnitude of the selection incentives. Since this is very close to the value added $(V A)$ model, the latter also performs satisfactorily in this respect. Moreover, the reference level will play a role for behavior and can now be used to steer selection incentives. A low reference implies that most schools benefit from attracting stronger pupils, while a high reference implies that most schools gain from attracting weaker pupils. An intermediate level - as in the value added model-imply that some schools gain and other schools lose from attracting better students. Interestingly, this may lead to efficient sorting. Schools with a higher slope than the reference slope perform better for stronger pupils and also have an incentive to attract the stronger pupils and refer the weaker ones; and schools with a lower slope than the reference slope perform better for weaker pupils and also get an incentive to attract them and to refer better pupils. Of

course, stronger segregation of pupils will result. The simulation results illustrate clearly the trade-off between different objectives that was already mentioned when we introduced the principle of NO INCENTIVES FOR PUPIL SELECTION.

\section{Conclusion}

Recent experiences have shown that introducing school accountability may create incentives for efficiency. It may also have undesirable side-effects, however, 
like pupil selection, even if test scores can be perfectly corrected for pupil characteristics. We have shown that a school financing scheme that rewards output also creates incentives for cream-skimming, unless the educational production function satisfies an (unrealistic) separability assumption. It is therefore necessary to consider explicitly the trade-off between the two objectives of improving performance and avoiding selection. We discuss the pros and cons of different compromise solutions and we have shown how information from the empirical educational production literature can be integrated in a coherent normative framework. This normative framework illustrates how the theory of fair allocation can also be applied to the design of financing schemes for institutions.

The empirical relevance of this analysis is illustrated with data on Flemish primary schools, for which the conflict between rewarding output and removing incentives for cream-skimming is shown to be empirically relevant. Given the manipulability of schemes that rely on information about the policy decisions of schools, one could argue in favor of what we have called "reference administration" schemes. To implement such schemes the regulator only needs information on the characteristics of the pupils. Our empirical results illustrate the importance of choosing a "correct" reference value for the administration variable. Choosing a low (high) reference value for the slope variable creates incentives for better treatment and selection of pupils with higher (lower) initial test scores and parental education. Picking an intermediate value (as is implicitly done by the value added model) will minimize the selection incentives and may even induce a kind of efficient sorting. In this empirical setting the value added-model therefore comes out as a reasonable compromise.

We have interpreted our axioms and results in terms of a funding scheme. This is not the only possible interpretation, however. One could as well argue that $s(\mathbf{x})$ represents only a performance measure, rather than a subsidy. Our principles remain valid in this measurement interpretation-INCENTIVES FOR GOOD ADMINISTRATION could be rebaptized as "performance sensitivity" and NO INCENTIVES FOR PUPIL SELECTION as "correction for pupil characteristics"and the impossibility result remains relevant in this setting. Even if the regulator is not willing to introduce accountability in the system (which may be the case in many European countries) and sticks to the idea of quality norms and control, the framework remains valid. It is natural to financially compensate schools with a socially disadvantaged pupil population, as it is more difficult for 
them to realize the required quality norms. In general however, it is not possible to compensate schools for their pupil population, while leaving the school autonomy to meet the quality criteria unaffected. The current framework can therefore shed a light on this question as well. 


\section{References}

[1] Arcidiacono, P. and C. Koedel, 2014, Race and college success: evidence from Missouri, American Economic Journal: Applied Economics 6(3), 2057 .

[2] Barlevy, G., and D. Neal, 2012, Pay for percentile, American Economic Review 102(5), 1805-1831.

[3] Burgess, S., C. Propper, H. Slater, and D. Wilson, 2005, Who wins and who loses from school accountability? The distribution of educational gain in English secondary schools. CMPO, Bristol: Working Paper 05/128.

[4] Burgess, S., C. Propper, and D. Wilson, 2007, The impact of school choice in England. Policy Studies 28(2), 129-143.

[5] Cawley, J., J. Heckman, and E. Vytlacil, 1999, On policies to reward the value added by educators, Review of Economics and Statistics 81(4), 720727.

[6] Chiang, H., 2009, How accountability pressure on failing schools affects student achievement, Journal of Public Economics 93, 1045-1057.

[7] Epple, D., and R. Romano, 2008, Educational vouchers and cream skimming, International Economic Review 49(4), 1395-1435.

[8] Figlio, D., and C. Rouse, 2006, Do accountability and voucher threats improve low-performing schools? Journal of Public Economics 90, 239255.

[9] Figlio, D., and J. Winicki, 2005, Food for thought: the effects of school accountability plans on school nutrition, Journal of Public Economics 89, 381-394.

[10] Fleurbaey, M., 2008, Fairness, Responsibility and Welfare, Oxford University Press.

[11] Hanushek, E., 2006, School resources, chapter 14 in, E., Hanushek, and F., Welch, eds., Handbook of the Economics of Education vol 2, Elsevier. 
[12] Hanushek, E., and M. Raymond, 2003, Lessons about the design of state accountability systems, in, P., Peterson, and M., West, eds., No Child Left Behind? The Politics and Practice of Accountability, Brookings.

[13] Hanushek, E. and M. Raymond, 2004, The effect of school accountability systems on the level and distribution of student achievement, Journal of the European Economic Association 2(2/3), 406-415.

[14] Hanushek, E. , and M. Raymond, 2005, Does school accountability lead to improved student performance? Journal of Policy Analysis and Management 24(2), 297-327.

[15] Jacob, B., 2005, Accountability, incentives and behavior: the impact of high-stakes testing in the Chicago public schools, Journal of Public Economics 89, 761-796.

[16] Kane, T., and D. Staiger, 2002, The promise and pitfalls of using imprecise school accountability measures, Journal of Economic Perspectives 16(4), 91-114.

[17] Ladd, H., and R. Walsh, 2002, Implementing value-added measures of school effectiveness: getting the incentives right, Economics of Education Review 21, 1-17.

[18] Lefranc, A., Pistolesi, N. and Trannoy, A., 2009, Equality of opportunity and luck: definitions and testable conditions, with an application to income in France, Journal of Public Economics 93, 1189-1207.

[19] Meyer, R., 1997, Value-added indicators of school performance: a primer, Economics of Education Review 16(3), 283-301.

[20] Mundlak, Y., 1978, On the pooling of time series and cross section data, Econometrica 46, 69-85.

[21] Neal, D., 2008, Designing incentive systems for schools, in, M., Springer, ed., Performance Incentives: Their Growing Impact on American K-12 Education, Brookings.

[22] Reback, R., 2008, Teaching to the rating: school accountability and the distribution of student achievement, Journal of Public Economics 92, 13941415 . 
[23] Schokkaert, E., G. Dhaene, and C. Van de Voorde, 1998, Risk adjustment and the trade-off between efficiency and risk selection: an application of the theory of fair compensation. Health Economics 7, 465-480.

[24] Schokkaert, E., and C. Van de Voorde, 2004, Risk selection and the specification of the conventional risk adjustment formula, Journal of Health Economics 23, 1237-1259.

[25] Schokkaert, E. and Van de Voorde, C., 2009, Direct versus indirect standardization in risk adjustment, Journal of Health Economics 28, 361-374.

[26] Semykina, A., and J. Wooldridge, 2010, Estimating panel data models in the presence of endogeneity and selection, Journal of Econometrics 157, 375-380.

[27] Taylor, J., and A., Ngoc Nguyen, 2006, An analysis of the value added by secondary schools in England: is the value added indicator of any value? Oxford Bulletin of Economics and Statistics 68(2), 203-224.

[28] Verbeek, M., and T., Nijman, 1992, Testing for selectivity bias in panel data models, International Economic Review 33, 681-703.

[29] West, M., and P., Peterson, 2006, The efficacy of choice threats within school accountability systems: results from legislatively induced experiments, Economic Journal 116, 46-62.

[30] Wooldridge, J., 1995, Selection corrections for panel data models under conditional mean independence assumptions, Journal of Econometrics 68, $115-132$.

[31] Wössmann, L., 2003, Schooling resources, educational institutions and student performance: the international evidence, Oxford Bulletin of Economics and Statistics 65(2), 117-170. 


\section{Proof of proposition 2}

A subsidy scheme can satisfy INCENTIVES FOR GOOD ADMINISTRATION and NO INCENTIVES FOR PUPIL SELECTION if and only if there exist functions $g$ : $\mathbb{R} \times B \rightarrow \mathbb{R}$ and $h: A \rightarrow \mathbb{R}$, with $g$ strictly increasing in its first argument, such that $f(a, b)=g(h(a), b)$, for all $x=(a, b)$ in $X$.

If the separability condition holds, it is possible to define a subsidy scheme $s$ such that each school subsidy $s_{j}$ is a strictly increasing function of $h\left(a_{j}\right)$ only. Such a scheme satisfies both axioms. We show the opposite.

Consider a subsidy scheme that satisfies INCENTIVES FOR GOOD ADMINISTRATION and NO INCENTIVES FOR PUPIL SELECTION. We show that, for arbitrary administrations $a, a^{\prime} \in A$ and backgrounds $b, b^{\prime} \in B$, we have

$$
f(a, b) \geq f\left(a^{\prime}, b\right) \Leftrightarrow f\left(a, b^{\prime}\right) \geq f\left(a^{\prime}, b^{\prime}\right) .
$$

This would indeed allow to properly define functions

1. $h: A \rightarrow \mathbb{R}$ with $h(a) \geq h\left(a^{\prime}\right)$ if $f(a, b) \geq f\left(a^{\prime}, b\right)$ for some $b \in B$, and

2. $g: \mathbb{R} \times B \rightarrow \mathbb{R}$ with $g(h(a), b)=f(a, b)$ for all $x=(a, b)$,

with $g$ strictly increasing in its first argument.

We proceed by contradiction. Suppose equation (19) does not hold, e.g., both $f(a, b) \geq f\left(a^{\prime}, b\right)$ and $f\left(a, b^{\prime}\right)<f\left(a^{\prime}, b^{\prime}\right)$ are true for some $a, a^{\prime} \in A$ and $b, b^{\prime} \in B$. (It is easy to verify the other direction using the same logic.) We can use these $a, a^{\prime} \in A$ and $b, b^{\prime} \in B$ to construct four states- $(a, b),\left(a^{\prime}, b\right),\left(a, b^{\prime}\right)$, and $\left(a^{\prime}, b^{\prime}\right)$ - for some school (tacitly assuming that school information remains constant for all other schools). We suppress subscripts and use $f(a, b)$ and (with slight abuse of notation) $s(a, b)$ to refer to the output and the subsidy of the school under consideration. Applying INCENTIVES FOR GOOD ADMINISTRATION twice, we must have

$$
s(a, b)-s\left(a^{\prime}, b\right) \geq 0 \text { and } s\left(a, b^{\prime}\right)-s\left(a^{\prime}, b^{\prime}\right)<0 .
$$

Applying No inCEntives for PUPIL SELECTIOn twice, we obtain

$$
s(a, b)=s\left(a, b^{\prime}\right) \text { and } s\left(a^{\prime}, b\right)=s\left(a^{\prime}, b^{\prime}\right),
$$

and, subtracting both equations, we get:

$$
s(a, b)-s\left(a^{\prime}, b\right)=s\left(a, b^{\prime}\right)-s\left(a^{\prime}, b^{\prime}\right) .
$$

Equation (20) and (21) are incompatible, a contradiction. 


\section{A derivation of the empirical subsidy schemes}

The per-capita and uncorrected output schemes are straightforward. We discuss the reference administration, reference background and value added scheme. A subsidy scheme is defined as

$$
s_{j}=1+\text { slope } \times\left(\widetilde{y}_{j}-\overline{\widetilde{y}}\right),
$$

with the slope defined by (17) for each scheme. We focus here on the difference $\widetilde{y}_{j}-\overline{\widetilde{y}}$.

We start from the empirical model

$$
\begin{aligned}
\bar{y}_{j}=\widehat{\beta}_{a}^{\prime} \bar{z}_{a, j}+\widehat{v}_{j}+\widehat{\beta}_{b, j}^{\prime} \bar{z}_{b, j} & =f(\underbrace{\bar{z}_{a, j}, \widehat{v}_{j}, \widehat{\beta}_{b, j}^{\prime}}_{a_{j}}, \underbrace{\bar{z}_{b, j}}_{b_{j}}) . \\
& =f(\underbrace{}_{\sim},
\end{aligned}
$$

The RA models use a reference administration, say $\widetilde{a}=\left(\widetilde{z}_{a}, \widetilde{v}, \widetilde{\beta}_{b}\right)$, to define the hypothetical output as

$$
\widetilde{y}_{j}=\bar{y}_{j}-f\left(\widetilde{a}, b_{j}\right)=\bar{y}_{j}-\left(\beta_{a}^{\prime} \widetilde{z}_{a}+\widetilde{v}+\widetilde{\beta}_{b}^{\prime} \bar{z}_{b, j}\right) .
$$

The average hypothetical output is equal to

$$
\overline{\widetilde{y}}=\bar{y}-\left(\beta_{a}^{\prime} \widetilde{z}_{a}+\widetilde{v}+\widetilde{\beta}_{b}^{\prime} \bar{z}_{b}\right),
$$

and the difference $\widetilde{y}_{j}-\overline{\widetilde{y}}$ is indeed equal to

$$
\left(\bar{y}_{j}-\bar{y}\right)-\widetilde{\beta}_{b}^{\prime}\left(\bar{z}_{b, j}-\bar{z}_{b}\right) .
$$

Starting from the same empirical model, the RB models replace $\bar{z}_{b, j}$ by a reference background $\widetilde{b}=\widetilde{z}_{b}$ to get

$$
\widetilde{y}_{j}=f\left(a_{j}, \widetilde{b}\right)=\widehat{\beta}_{a}^{\prime} \bar{z}_{a, j}+\widehat{v}_{j}+\widehat{\beta}_{b, j}^{\prime} \widetilde{z}_{b} .
$$

The OLS estimate for $\widehat{v}_{j}$ is

$$
\widehat{v}_{j}=\bar{y}_{j}-\widehat{\beta}_{a}^{\prime} \bar{z}_{a, j}-\widehat{\beta}_{b, j}^{\prime} \bar{z}_{b, j},
$$

and we can rewrite the hypothetical output as

$$
\widetilde{y}_{j}=\bar{y}_{j}-\widehat{\beta}_{b, j}^{\prime}\left(\bar{z}_{b, j}-\widetilde{z}_{b}\right)
$$

The average is given by

$$
\overline{\widetilde{y}}_{j}=\bar{y}-\overline{\widehat{\beta}_{b, j}^{\prime}\left(\bar{z}_{b, j}-\widetilde{z}_{b}\right)},
$$


and the difference $\widetilde{y}_{j}-\overline{\widetilde{y}}_{j}$ indeed becomes

$$
\left(\bar{y}_{j}-\bar{y}\right)-\widehat{\beta}_{b, j}^{\prime}\left(\bar{z}_{b, j}-\widetilde{z}_{b}\right)+\overline{\widehat{\beta}_{b, j}^{\prime}\left(\bar{z}_{b, j}-\widetilde{z}_{b}\right)} .
$$

Finally, for the value-added (VA) model we have

$$
\widetilde{y}_{j}=\widehat{\beta}_{a}^{V A \prime} \bar{z}_{a, j}+\widehat{v}_{j}^{V A},
$$

with the OLS estimate of $v_{j}^{V A}$ in (18) given by

$$
\widehat{v}_{j}^{V A}=\bar{y}_{j}-\widehat{\beta}_{a}^{V A \prime} \bar{z}_{a, j}-\widehat{\beta}_{b}^{V A \prime} \bar{z}_{b, j} .
$$

Plugging in the OLS estimate, corrected output becomes

$$
\widetilde{y}_{j}=\bar{y}_{j}-\widehat{\beta}_{b}^{V A \prime} \bar{z}_{b, j} \text {. }
$$

Averaging the corrected output, we get

$$
\overline{\widetilde{y}}=\bar{y}-\widehat{\beta}_{b}^{V A \prime} \bar{z}_{b}
$$

and the difference $\widetilde{y}_{j}-\overline{\widetilde{y}}$ indeed reduces to

$$
\left(\bar{y}_{j}-\bar{y}\right)-\widehat{\beta}_{b}^{V A \prime}\left(\bar{z}_{b, j}-\bar{z}_{b}\right) .
$$




\section{Figures and tables}

Figure 1. Aligning performance and selection incentives: mission impossible

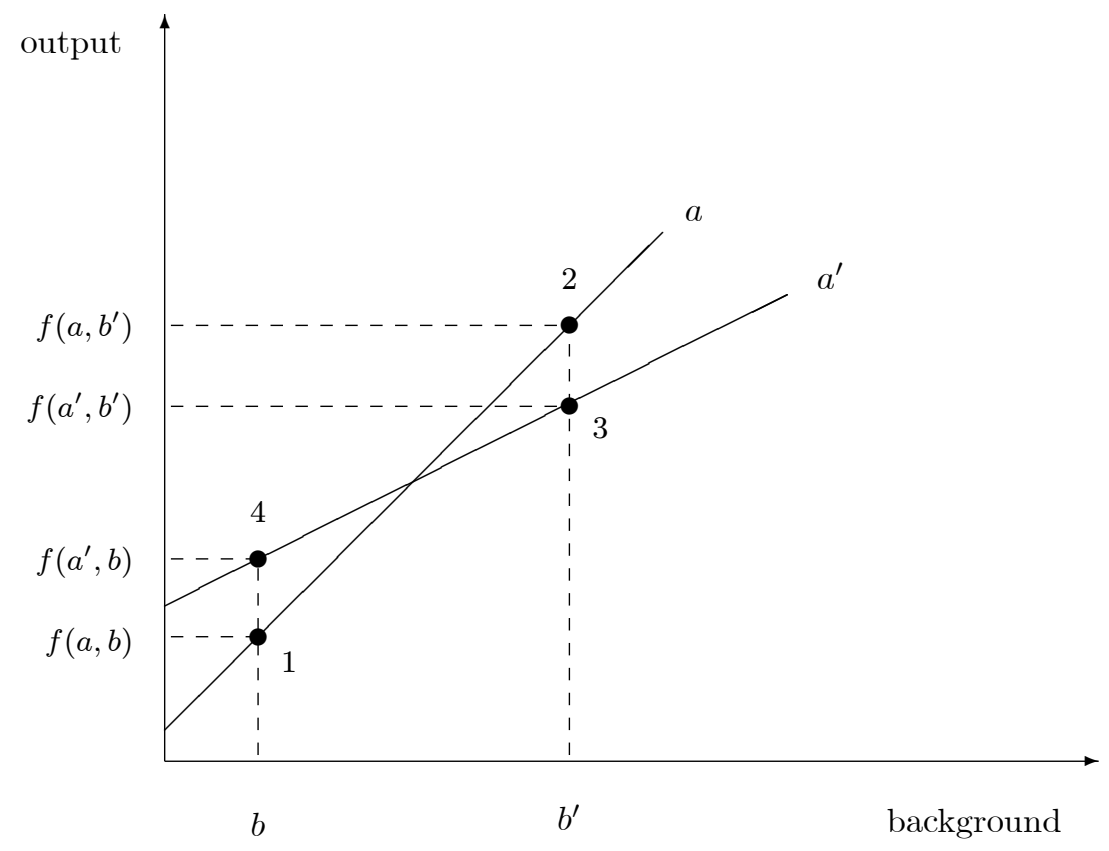




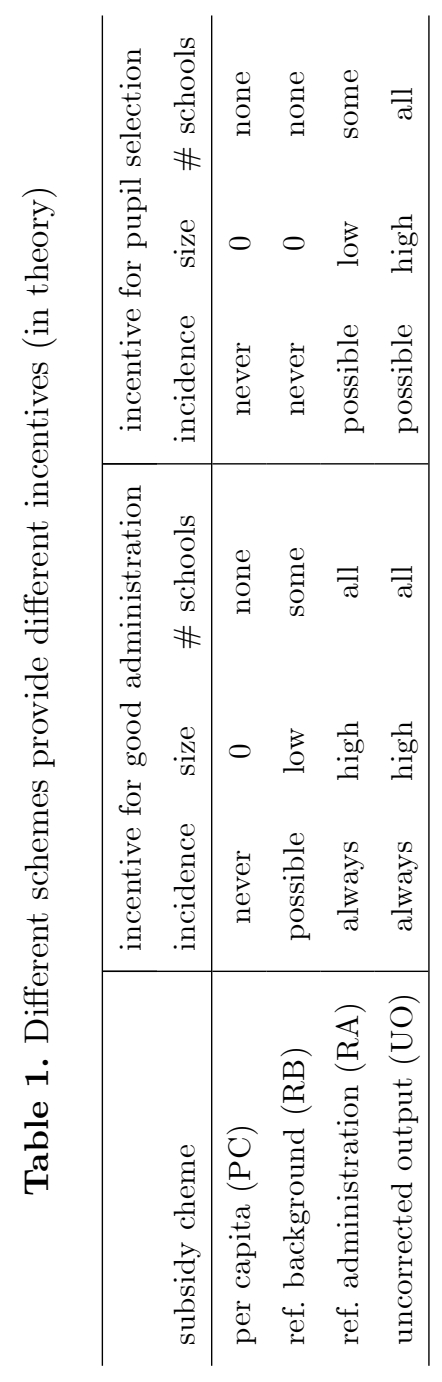




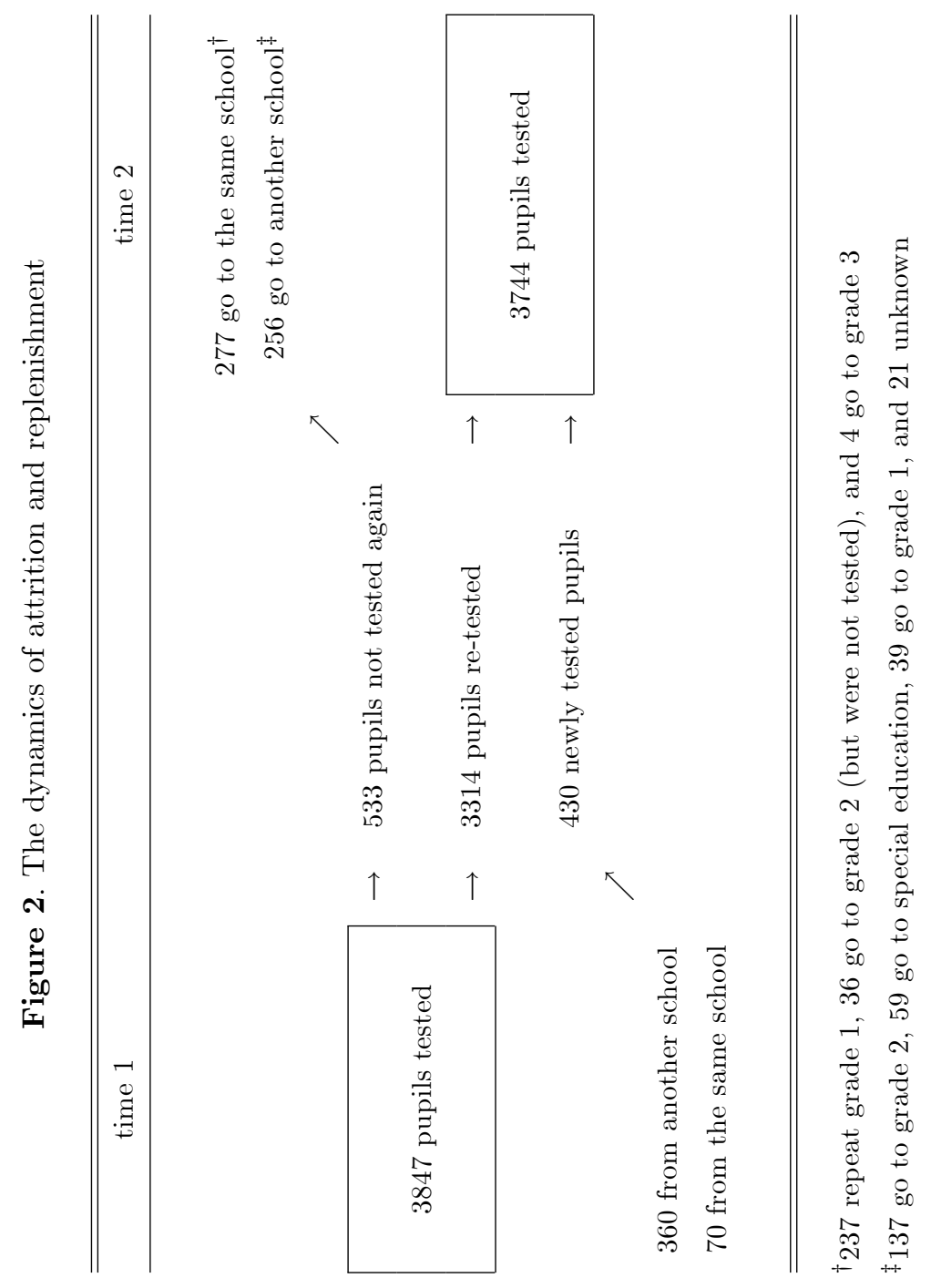




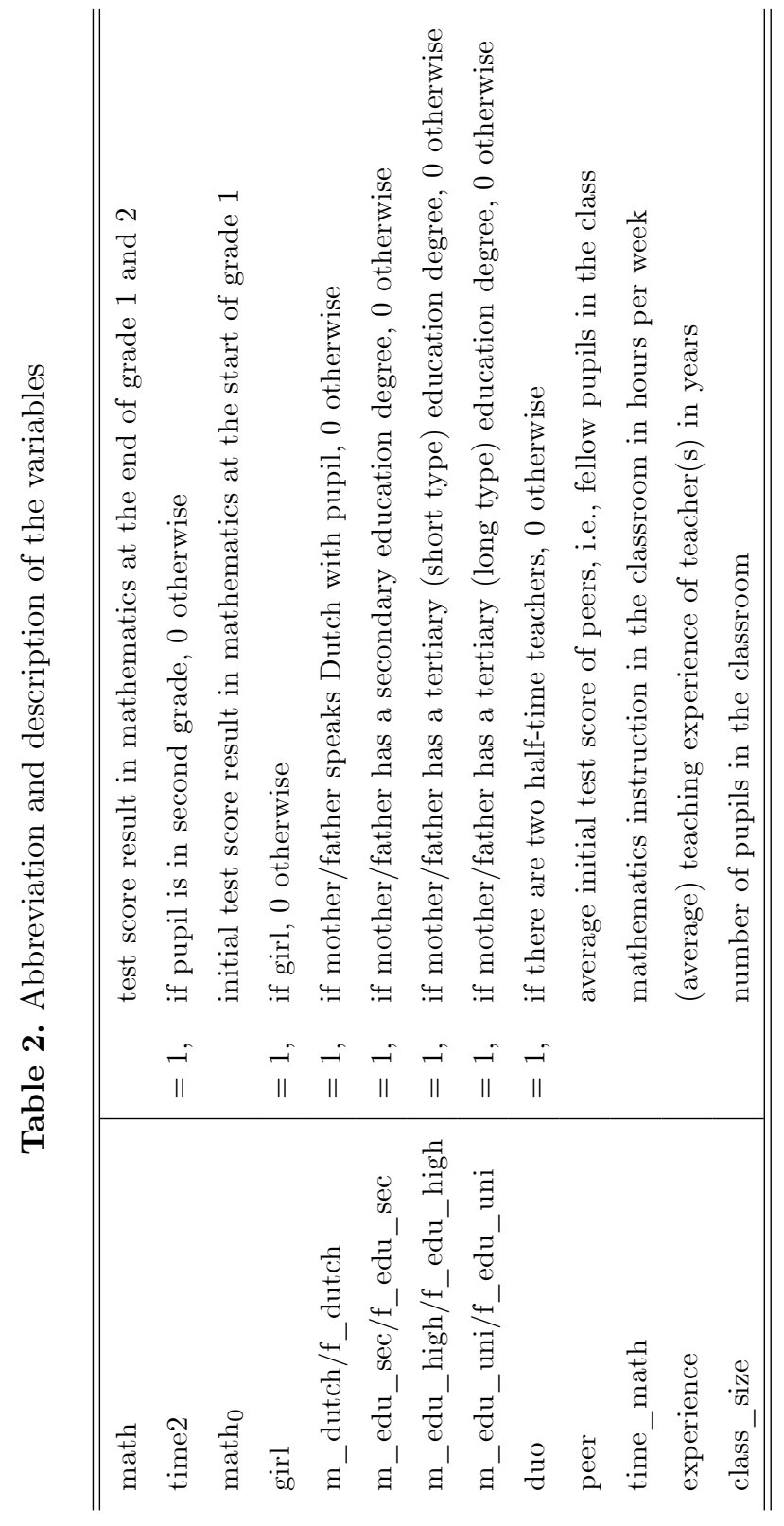


Table 3a. Summary statistics for pupil variables.

\begin{tabular}{|c|c|c|c|c|c|}
\hline math score & mean & std.dev. & p10 & median & p90 \\
\hline grade 1 & 8.75 & 1.00 & 7.44 & 8.77 & 10.06 \\
\hline grade 2 & 9.71 & 1.00 & 8.43 & 9.71 & 11.04 \\
\hline initial math score & mean & std.dev. & $\mathrm{p} 10$ & median & p90 \\
\hline grade 1 & 8.05 & 1.02 & 6.71 & 8.13 & 9.31 \\
\hline grade 2 & 8.16 & 0.97 & 6.85 & 8.22 & 9.37 \\
\hline sex & $=$ boy & $=$ girl & & & \\
\hline grade 1 & $50.54 \%$ & $49.46 \%$ & & & \\
\hline grade 2 & $50.58 \%$ & $49.15 \%$ & & & \\
\hline language mother & $=$ dutch & $\neq$ dutch & miss. & & \\
\hline grade 1 & $86.82 \%$ & $8.61 \%$ & $4.57 \%$ & & \\
\hline grade 2 & $85.69 \%$ & $9.12 \%$ & $5.19 \%$ & & \\
\hline language father & $=$ dutch & $\neq$ dutch & miss. & & \\
\hline grade 1 & $84.80 \%$ & $10.29 \%$ & $4.91 \%$ & & \\
\hline grade 2 & $84.54 \%$ & $9.90 \%$ & $5.56 \%$ & & \\
\hline $\begin{array}{l}\text { mother's highest } \\
\text { degree }\end{array}$ & $<2^{\text {ary }}$ & $2^{\text {ary }}$ & $\begin{array}{c}3^{\text {ary }} \\
(\neq \text { univ. })\end{array}$ & $\begin{array}{c}3^{\text {ary }} \\
\text { (=univ.) }\end{array}$ & miss. \\
\hline grade 1 & $19.25 \%$ & $33.94 \%$ & $29.06 \%$ & $8.72 \%$ & $9.03 \%$ \\
\hline grade 2 & $16.54 \%$ & $33.56 \%$ & $30.41 \%$ & $10.00 \%$ & $9.49 \%$ \\
\hline $\begin{array}{l}\text { father's highest } \\
\text { degree }\end{array}$ & $<2^{\text {ary }}$ & $2^{\text {ary }}$ & $\begin{array}{c}3^{\text {ary }} \\
(\neq \text { univ. })\end{array}$ & $\begin{array}{c}3^{\text {ary }} \\
\text { (=univ.) }\end{array}$ & miss. \\
\hline grade 1 & $19.29 \%$ & $34.74 \%$ & $21.00 \%$ & $12.07 \%$ & $12.90 \%$ \\
\hline grade 2 & $17.49 \%$ & $34.78 \%$ & $22.10 \%$ & $13.39 \%$ & $12.24 \%$ \\
\hline
\end{tabular}


Table 3b. Summary statistics for class variables

\begin{tabular}{cccccc}
\hline \hline \# of teachers & $=1$ & $=2$ & & & \\
\hline grade 1 & $89.33 \%$ & $10.67 \%$ & & & \\
grade 2 & $86.27 \%$ & $13.73 \%$ & & & \\
\hline \hline instruction time & mean & std.dev. & p10 & median & p90 \\
\hline grade 1 & 6.17 & 0.86 & 5 & 6 & 7 \\
grade 2 & 6.30 & 0.87 & 5.5 & 6 & 7 \\
\hline \hline total experience & mean & std.dev. & p10 & median & p90 \\
\hline grade 1 & 15.15 & 8.95 & 4 & 15 & 28 \\
grade 2 & 17.67 & 9.37 & 4 & 18 & 30 \\
\hline \hline class size & mean & std.dev. & p10 & median & p90 \\
\hline grade 1 & 20.12 & 3.80 & 15 & 20 & 26 \\
grade 2 & 20.24 & 4.08 & 15 & 20 & 26 \\
\hline \hline peer effect & mean & std.dev. & p10 & median & p90 \\
\hline grade 1 & 8.05 & 0.47 & 7.48 & 8.13 & 8.55 \\
grade 2 & 8.16 & 0.48 & 7.62 & 8.27 & 8.64 \\
\hline \hline
\end{tabular}


Table 4. Explaining math test scores

\begin{tabular}{|c|c|c|c|c|c|c|c|c|}
\hline \multirow[t]{2}{*}{ math } & \multicolumn{2}{|c|}{ model a } & \multicolumn{2}{|c|}{ model b } & \multicolumn{2}{|c|}{ model c } & \multicolumn{2}{|c|}{ model d } \\
\hline & coeff. & $\mathrm{p}>|\mathrm{t}|$ & coeff. & $\mathrm{p}>|\mathrm{t}|$ & coeff. & $\mathrm{p}>|\mathrm{t}|$ & coeff. & $\mathrm{p}>|\mathrm{t}|$ \\
\hline math $_{0}$ & 0.67 & 0.00 & & & 0.64 & 0.00 & 0.64 & 0.00 \\
\hline girl & & & -0.26 & 0.00 & -0.24 & 0.00 & -0.24 & 0.00 \\
\hline $\mathrm{m} \_$dutch & & & 0.16 & 0.01 & -0.13 & 0.01 & -0.13 & 0.02 \\
\hline f_dutch & & & 0.09 & 0.13 & -0.07 & 0.20 & -0.06 & 0.22 \\
\hline m_edu_sec & & & 0.15 & 0.00 & 0.00 & 0.95 & 0.00 & 0.96 \\
\hline m_edu_high & & & 0.45 & 0.00 & 0.10 & 0.01 & 0.10 & 0.01 \\
\hline m_edu_uni & & & 0.52 & 0.00 & 0.19 & 0.00 & 0.19 & 0.00 \\
\hline f_edu_sec & & & 0.07 & 0.04 & 0.06 & 0.07 & 0.06 & 0.07 \\
\hline f_edu_high & & & 0.25 & 0.05 & 0.14 & 0.00 & 0.13 & 0.00 \\
\hline f_edu_uni & & & 0.38 & 0.06 & 0.24 & 0.00 & 0.23 & 0.00 \\
\hline duo & & & & & & & -0.10 & 0.26 \\
\hline peer & & & & & & & 0.13 & 0.29 \\
\hline time_math & & & & & & & 0.09 & 0.10 \\
\hline experience & & & & & & & 0.00 & 0.47 \\
\hline class_size & & & & & & & 0.01 & 0.30 \\
\hline$R^{2}$ & & 0.61 & & 0.41 & & 0.64 & & 0.64 \\
\hline \# observations & & 5817 & & 5817 & & 5817 & & 5817 \\
\hline
\end{tabular}


Table 5. Robustness for sample selection and sorting

\begin{tabular}{|c|c|c|c|c|c|c|}
\hline \multirow[t]{2}{*}{ math } & \multicolumn{2}{|c|}{ model d } & \multicolumn{2}{|c|}{ model e } & \multicolumn{2}{|c|}{ model $\mathrm{f}$} \\
\hline & coeff. & $\mathrm{p}>|\mathrm{t}|$ & coeff. & $\mathrm{p}>|\mathrm{t}|$ & coeff. & $\mathrm{p}>|\mathrm{t}|$ \\
\hline math $_{0}$ & 0.64 & 0.00 & 0.63 & 0.00 & 0.64 & 0.00 \\
\hline girl & -0.24 & 0.00 & -0.25 & 0.00 & -0.24 & 0.00 \\
\hline m_dutch & -0.13 & 0.02 & -0.13 & 0.06 & -0.13 & 0.04 \\
\hline f_dutch & -0.06 & 0.22 & -0.07 & 0.21 & -0.03 & 0.58 \\
\hline $\mathrm{m}_{-}$edu_sec & 0.00 & 0.96 & -0.01 & 0.78 & 0.02 & 0.66 \\
\hline m_edu_high & 0.10 & 0.01 & 0.09 & 0.04 & 0.12 & 0.01 \\
\hline m_edu_uni & 0.19 & 0.00 & 0.18 & 0.00 & 0.20 & 0.01 \\
\hline f_edu_sec & 0.06 & 0.07 & 0.06 & 0.07 & 0.07 & 0.11 \\
\hline f_edu_high & 0.13 & 0.00 & 0.13 & 0.00 & 0.14 & 0.00 \\
\hline f_edu_uni & 0.23 & 0.00 & 0.25 & 0.00 & 0.24 & 0.00 \\
\hline duo & -0.10 & 0.26 & -0.07 & 0.55 & -0.14 & 0.10 \\
\hline peer & 0.13 & 0.29 & 0.10 & 0.43 & 0.09 & 0.53 \\
\hline time_math & 0.09 & 0.10 & 0.08 & 0.20 & 0.10 & 0.05 \\
\hline experience & 0.00 & 0.47 & 0.00 & 0.38 & 0.00 & 0.48 \\
\hline class_size & 0.01 & 0.30 & 0.01 & 0.29 & -0.01 & 0.58 \\
\hline $\operatorname{gr} 1$ & & & -0.13 & 0.30 & -0.02 & 0.83 \\
\hline gr $1 \times$ time 2 & & & -0.08 & 0.14 & 0.08 & 0.43 \\
\hline $\operatorname{gr} 2$ & & & -0.14 & 0.24 & -0.02 & 0.69 \\
\hline gr $2 \times$ time 2 & & & 0.09 & 0.56 & -0.03 & 0.80 \\
\hline catholic & & & & & 0.11 & 0.29 \\
\hline$R^{2}$ & & 0.64 & & 0.64 & & 0.60 \\
\hline \# observations & & 5817 & & 5817 & & 4457 \\
\hline
\end{tabular}

constant, time dummy, school dummies (except f), and group means included, but not reported. 
Table 6. An academic index

\begin{tabular}{l|cc}
\hline \hline math & \multicolumn{2}{|c}{ index } \\
\hline & coeff. & $\mathrm{p}>|\mathrm{t}|$ \\
\hline girl $^{\dagger}$ & -1.00 & \\
m_dutch & -0.19 & 0.00 \\
$\mathrm{f} \_$dutch & -0.36 & 0.00 \\
m_edu_sec & -0.01 & 0.88 \\
m_edu_high & 0.49 & 0.00 \\
m_edu_uni & 1.03 & 0.00 \\
f_edu_sec & 0.12 & 0.13 \\
f_edu_high & 0.36 & 0.00 \\
f_edu_uni & 0.57 & 0.00 \\
\hline \hline
\end{tabular}


Table 7. Educational production is not likely to be separable

\begin{tabular}{l|ccc}
\hline \hline & $\chi^{2}$-value & df & Prob $>\chi^{2}$ \\
\hline initial test score & 298.11 & 110 & 0.00 \\
girl & 259.67 & 110 & 0.00 \\
mother dutch & 554.76 & 110 & 0.00 \\
father dutch & 496.68 & 110 & 0.00 \\
education mother & 1428.04 & 305 & 0.00 \\
education father & 1222.27 & 305 & 0.00 \\
\hline all variables & $1.7 \times 10^{10}$ & 964 & 0.00 \\
\hline \hline
\end{tabular}




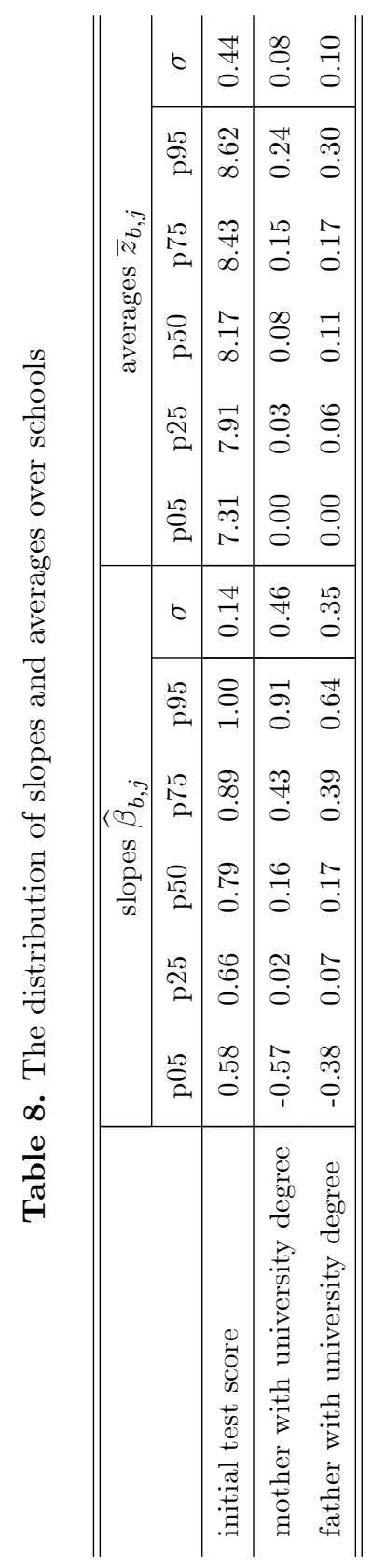


Table 9. Incentives with respect to initial test scores

Table 9a. Incentives for good administration when changing the initial test score slope

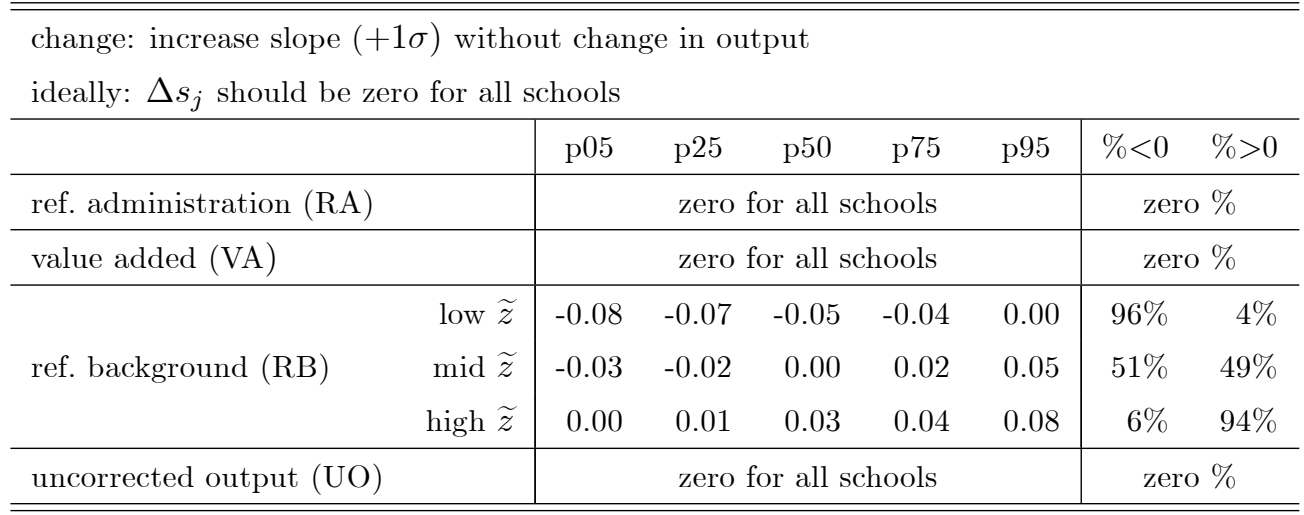

Table 9b. Incentives for pupil selection when changing the initial test score distribution change: attract pupils with a higher initial test scores $(+1 \sigma)$ ideally: $\Delta s_{j}$ should be zero for all schools

\begin{tabular}{|c|c|c|c|c|c|c|c|c|}
\hline & & $\mathrm{p} 05$ & p25 & $\mathrm{p} 50$ & $\mathrm{p} 75$ & $\mathrm{p} 95$ & $\%<0$ & $\%>0$ \\
\hline \multirow{3}{*}{ ref. administration (RA) } & low $\widetilde{\beta}$ & 0.00 & 0.01 & 0.04 & 0.05 & 0.08 & $6 \%$ & $94 \%$ \\
\hline & $\operatorname{mid} \widetilde{\beta}$ & -0.04 & -0.02 & 0.00 & 0.02 & 0.04 & $51 \%$ & $49 \%$ \\
\hline & $\operatorname{high} \widetilde{\beta}$ & -0.08 & -0.06 & -0.04 & -0.02 & 0.00 & $97 \%$ & $3 \%$ \\
\hline value added (VA) & & -0.03 & -0.02 & 0.00 & 0.02 & 0.04 & $48 \%$ & $52 \%$ \\
\hline ref. background (RB) & & \multicolumn{5}{|c|}{ zero for all schools } & \multicolumn{2}{|c|}{ zero $\%$} \\
\hline uncorrected output (UO) & & 0.10 & 0.11 & 0.14 & 0.16 & 0.18 & $0 \%$ & $100 \%$ \\
\hline
\end{tabular}


Table 10. Incentives with respect to parental education

Table 10a. Incentives for good administration when changing the parental education slope change: increase slope $(+1 \sigma)$ without change in output ideally: $\Delta s_{j}$ should be zero for all schools

\begin{tabular}{|c|c|c|c|c|c|c|c|c|}
\hline & & p05 & $\mathrm{p} 25$ & p50 & p75 & p95 & $\%<0$ & $\%>0$ \\
\hline ref. administration (RA) & & \multicolumn{5}{|c|}{ zero for all schools } & \multicolumn{2}{|c|}{ zero $\%$} \\
\hline \multicolumn{2}{|l|}{ value added (VA) } & \multicolumn{5}{|c|}{ zero for all schools } & \multicolumn{2}{|c|}{ zero $\%$} \\
\hline \multirow{3}{*}{ ref. background (RB) } & low $\widetilde{z}$ & -0.08 & -0.05 & -0.03 & -0.01 & 0.00 & $100 \%$ & $0 \%$ \\
\hline & $\operatorname{mid} \widetilde{z}$ & -0.05 & -0.02 & 0.00 & 0.02 & 0.03 & $48 \%$ & $52 \%$ \\
\hline & $\operatorname{high} \widetilde{z}$ & 0.00 & 0.04 & 0.06 & 0.07 & 0.08 & $4 \%$ & $96 \%$ \\
\hline uncorrected output (UO) & & \multicolumn{5}{|c|}{ zero for all schools } & \multicolumn{2}{|c|}{ zero $\%$} \\
\hline
\end{tabular}

Table 10b. Incentives for pupil selection when changing the parental education distribution change: attract pupils with highly educated parents $(+1 \sigma)$ ideally: $\Delta s_{j}$ should be zero for all schools

\begin{tabular}{|c|c|c|c|c|c|c|c|c|}
\hline & & p05 & p25 & $\mathrm{p} 50$ & p75 & p95 & $\%<0$ & $\%>0$ \\
\hline \multirow{3}{*}{ ref. administration (RA) } & low $\beta$ & 0.03 & 0.04 & 0.04 & 0.06 & 0.07 & $0 \%$ & $100 \%$ \\
\hline & $\operatorname{mid} \widetilde{\beta}$ & -0.02 & -0.01 & 0.00 & 0.01 & 0.03 & $48 \%$ & $52 \%$ \\
\hline & $\operatorname{high} \widetilde{\beta}$ & -0.06 & -0.05 & -0.04 & -0.03 & -0.01 & $100 \%$ & $0 \%$ \\
\hline value added (VA) & & -0.02 & -0.01 & 0.00 & 0.01 & 0.02 & $52 \%$ & $48 \%$ \\
\hline ref. background (RB) & & \multicolumn{5}{|c|}{ zero for all schools } & \multicolumn{2}{|c|}{ zero $\%$} \\
\hline uncorrected output (UO) & & -0.01 & 0.00 & 0.01 & 0.02 & 0.04 & $16 \%$ & $84 \%$ \\
\hline
\end{tabular}

